\title{
ANÁLISE INICIAL DE DIFERENTES TÉCNICAS NO CONTROLE DE MATOCOMPETIÇÃO EM UM TRECHO DE REFLORESTAMENTO DA MATA CILIAR EM PRESIDENTE PRUDENTE
}

\author{
Fabiana Lima Salomão ${ }^{1}$, Renato de Araújo Ferreira ${ }^{2}$ \\ ${ }^{1}$ Universidade do Oeste Paulista- UNOESTE, Engenharia Ambiental e Sanitária, Presidente Prudente - SP. \\ ${ }^{2}$ Centro Estadual de Educação Tecnológica Paula Souza, Escola Técnica Estadual Prof. Dr. Antonio Eufrásio de Toledo - \\ ETEC, Presidente Prudente, SP. \\ E-mail: faby.salomao@hotmail.com
}

\section{RESUMO}

Durante o processo de reflorestamento, os principais inibidores do desenvolvimento das mudas na fase inicial são as formigas cortadeiras e ervas daninhas. Caso não sejam controlados, podem ocasionar morte das mudas. Desta forma, o objetivo deste estudo foi analisar diferentes técnicas para o controle de ervas daninha em um trecho de reflorestamento da Mata Ciliar na Etec Prof. Dr. Antonio Eufrásio de Toledo. Foram empregadas técnicas biológicas (Canavalia ensiformis e Crotalaria spectabilis ) e físicas (sombrite e lona plástica) na metodologia de controle. As técnicas que obtiveram melhores resultados foram nos métodos físicos. Concluindo que os métodos físicos utilizados apresentaram melhores resultados, pois as técnicas de sombrites e lonas plásticas respectivamente impossibilitaram parcialmente e totalmente a passagem de luminosidade que impediram a germinação e/ou desenvolvimento das ervas daninhas.

Palavras-chave: Reflorestamento, mata ciliar, ervas daninhas, técnica biológica, técnica física.

\section{INITIAL ANALYSIS OF DIFFERENT TECHNIQUES IN CONTROL OF MATOCOMPETITION IN A STRETCH OF REFORESTATION OF RIPARIAN FOREST IN PRESIDENTE PRUDENTE}

\begin{abstract}
During the reforestation process, the main inhibitors of the development of early-stage seedlings are leaf-cutting ants and weeds. If they are not controlled, they can cause death of the seedlings. In this way, the objective of this study was to analyze different techniques for the control of weeds in a section of reforestation of the Riparian Forest in Etec Prof. Dr. Antonio Eufrásio de Toledo. Biological techniques (Canavalia ensiformis e Crotalaria spectabilis) and physical (sombrite and plastic canvas) techniques were employed in the control methodology. The techniques that obtained the best results were in the physical methods. In conclusion, the physical methods used showed better results, because the sombrites and plastic canvases respectively partially and completely prevented the passage of light that prevented the germination and/or development of weeds.
\end{abstract}

Keywords: Reforestation, riparian forest, weeds, biological technique, physical technique. 


\section{INTRODUÇÃO}

As florestas existentes no território nacional, e demais formas de vegetação, trazem benefícios aos habitantes do mundo todo, contribuindo para a melhoria do ar, solo, água e dos seres vivos. Segundo Lei no 12.651 de 25 de maio de 2012, na propriedade rural existem duas áreas destinadas à preservação da flora e da fauna, sendo a Reserva Legal (RL) e a Área de Preservação Permanente (APP).

A vegetação existente na Área de Preservação Permanente, as margens de rios, possuem vários nomes, sendo o mais comum "Matas ciliares", uma referência aos cílios que protegem os olhos. São extremamente importantes, pois estabiliza o solo as margens dos cursos d'água, evitando erosões ou assoreamento, preservando a flora e a fauna.

Devido as atividades, principalmente agrícolas, realizadas pelo homem, diversas Matas Ciliares foram desmatadas, dificultando sua capacidade natural de regeneração, tornando-a caracterizada como degradada. Para reparar o dano é necessário intervir de tal forma a favorecer a existência de uma nova floresta no futuro. São várias as técnicas utilizadas para atingir esse objetivo, sendo necessário avaliar o grau de degradação, assim como as condições ecológicas do local e áreas vizinhas. A técnica mais empregada é o reflorestamento através do plantio de mudas.

Antes e após a implantação do reflorestamento, os maiores agentes que podem dificultar o desenvolvimento das mudas são as formigas cortadeiras e ervas daninhas. As ervas daninhas inibe o desenvolvimento das mudas, uma vez que compete por água, luz e nutrientes, podendo levar facilmente a morte das mudas (EMBRAPA, 2013).

O controle de ervas daninhas pode ser feito de várias formas, sendo biológica, mecânica, química e física (LORENZI, 2006). O controle químico, ou seja, mediado por herbicidas, é o mais empregado. No entanto na área de Preservação Permanente é aconselhável não utilizar estes agentes químicos, uma vez que podem gerar a contaminação do curso d'água, sendo necessário recorrer a outras técnicas.

Dessa forma, o presente trabalho teve como objetivo analisar diferentes técnicas alternativas para o controle de ervas daninhas em um trecho de reflorestamento da mata ciliar.

\section{METODOLOGIA}

O trabalho foi realizado na Escola Técnica - ETEC "Prof. Dr. Antonio Eufrásio de Toledo", pertencente ao Centro Estadual de Educação Tecnológica Paula Souza - CEETEPS, localizada na Rodovia Raposo Tavares km 561, município de Presidente Prudente/SP, cujas coordenadas geográficas são $22^{\circ} 10^{\prime} 38.39^{\prime \prime}$ e e 51은 $22^{\prime} 45.39^{\prime \prime}$.

A propriedade possui área total de 217,80 hectares. Conforme levantamento planimétrico, a área do espelho d'agua da represa é de $754 \mathrm{~m}^{2}$ e a Área de Preservação Permanente é de $13185,22 \mathrm{~m}^{2}$. A área destinada à avaliação possui $300 \mathrm{~m}^{2}$ (10x30). O clima da região tem temperatura anual média mínima de 14 으, média de 23,6 으 e máxima 31으; pluviosidade média anual de 1254.9 mm e classificação climática Koeppen do tipo Aw e altitude de 460m (CEPAGRI, 2017). O solo da região é o Argissolo (IBGE, 2001). O bioma local é de Mata Atlântica do tipo Floresta Estacional Semidecídua (IBGE, 2004ab)

Inicialmente foi realizada a retirada do Colonião (Panicum maximum) por meio de roçada semi-mecanizada. Na sequência, foi feito o coroamento, por meio da retirada da vegetação sobeja, no local a ser plantada a muda, formando uma região circular de $1 \mathrm{~m}$ de diâmetro. Após o preparo do local, iniciou a abertura dos berços, de forma manual com uso de cavadeira, tendo os berços as seguintes dimensões: $20 \mathrm{~cm}$ de diâmetro e $40 \mathrm{~cm}$ de profundidade. Junto ao solo removido durante a abertura dos berços foram acrescentados os fertilizantes de base. A recomendação de calagem e adubação segue a metodologia de Raij et al (1997). Conforme os resultados da análise, não foi necessário a calagem. Já a adubação consistiu ao equivalente a 40 $\mathrm{kg} /$ ha de Nitrogênio (N) e 1 kg/ha Boro (B), respectivamente 88,88 kg/ha de Uréia (13,34g/planta) 
e 5,74 Kg/ha de Ácido Bórico (3,44g/planta). A adubação com uso da uréia foi parcelada em quatro ocasiões, sendo no plantio, após 3, 6 e 12 meses após o plantio das mudas.

Logo após adubação realizou-se o plantio das mudas. Em seguida, foi feita uma "bacia", próximo ao colo da muda, com o objetivo de reter a água. Por fim foi realizada a irrigação no mesmo dia, com uma média de 2 litros de água por planta, de forma manual.

O reflorestamento heterogêneo consistiu o plantio de várias espécies, sendo: amora (Morus nigra), angico (Anadenanthera colubrina), babosa-branca (Cordia superba), calabura (Muntingia calabura), canela-pimenta (Ocotea puberula), canivete (Erythrina velutina), colorau (Bixa orellana), dedaleiro (Lafoensia pacari), embaúba (Cecropia pachystachya), guapuruvu (Schizolobium parahyba), ingá (Inga edulis), ingá-pequeno (Inga vera), ipê-branco (Handroanthus roseoalba), ipê-roxo (Handroanthus avallanedae), jenipapo (Genipa americana), jerivá (Syagrus romanzoffiana), lixa (Curatella americana), monguba (Pachira aquatica), oiti (Licania tomentosa), pau-ferro (Caesalpinia ferrea), pau-pólvora (Trema micranta), pau-viola (Cyntharexyllum myrianthum), saboneteira (Sapindus saponária), sangra d'água (Croton urucurana), sibipiruna (Caesalpinia pluviosa), goiaba (Psidium guajava) e pitanga (Eugenia uniflora). O reflorestamento foi realizado conforme recomendação de Lorenzi, 2010 e RAMOS, 2008.

O experimento utilizou o delineamento em Bloco Casualizado (DBC), com 5 tratamentos, 3 repetições com 3 plantas por repetição, totalizando 45 plantas. Os tratamentos empregados foram: 1= feijão de porco (Canavalia ensiformis), 2= crotalária (Crotalaria spectabilis), 3= sombrite, $4=$ lona plástica e $5=$ testemunha (Coroamento manual com enxada) (Figura 1).

Figura 1. Relação dos tratamentos do experimento

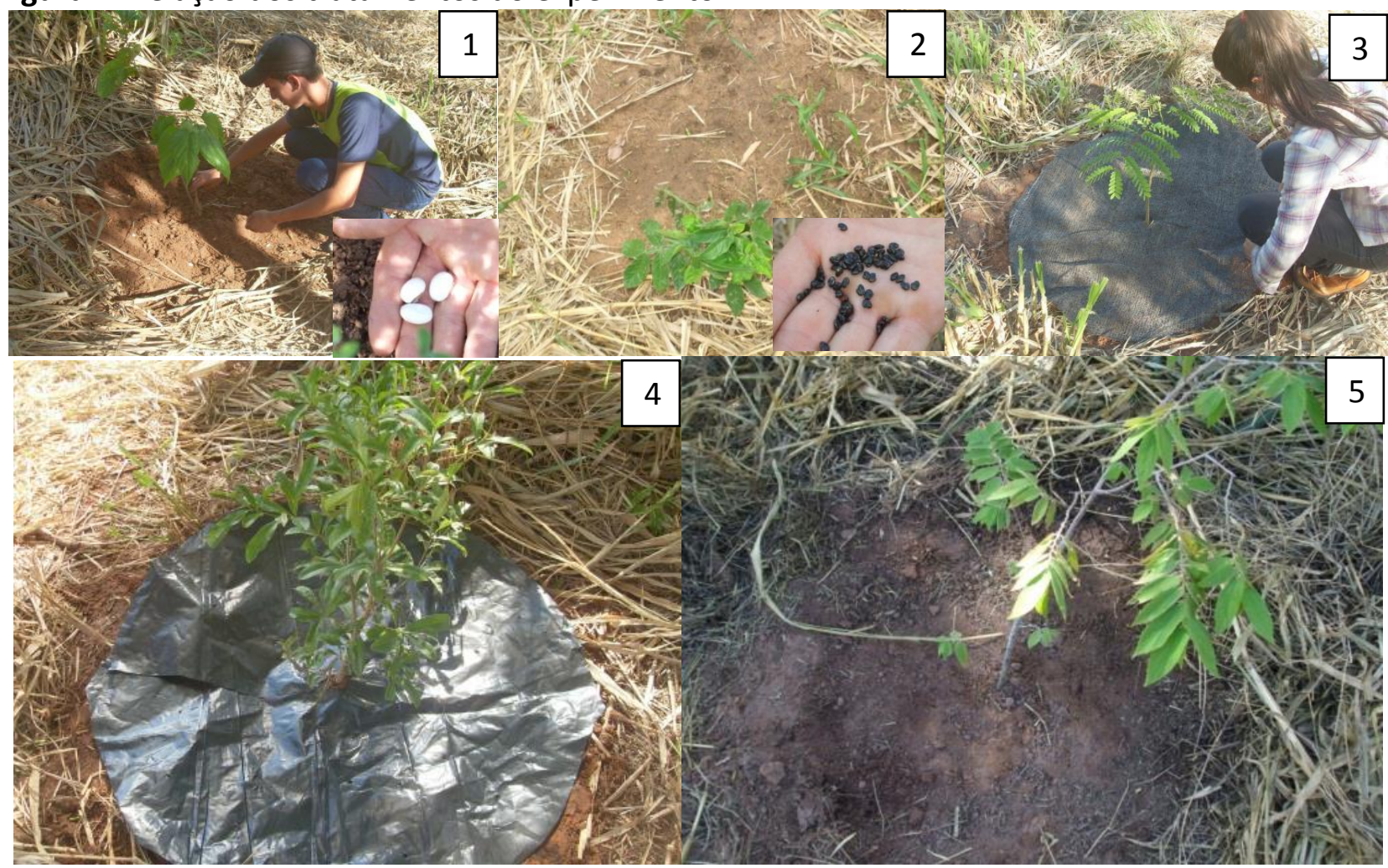

(Fonte: Autores).

Após 15 dias da implantação do experimento, iniciaram-se as avaliações. Foram realizadas três avaliações, com intervalos de 15 dias. Para realizar as avaliações utilizou-se um arco de PVC (Figura 2), com diâmetro de $15 \mathrm{~cm}$ e área de 176, $71 \mathrm{~cm}^{2}$. Em cada avaliação o arco era colocado ao lado da muda e era feita a contagem e anotação da quantidade de plântulas de ervas daninhas. 
Figura 2. Metodologia de avaliação com uso do arco em PVC

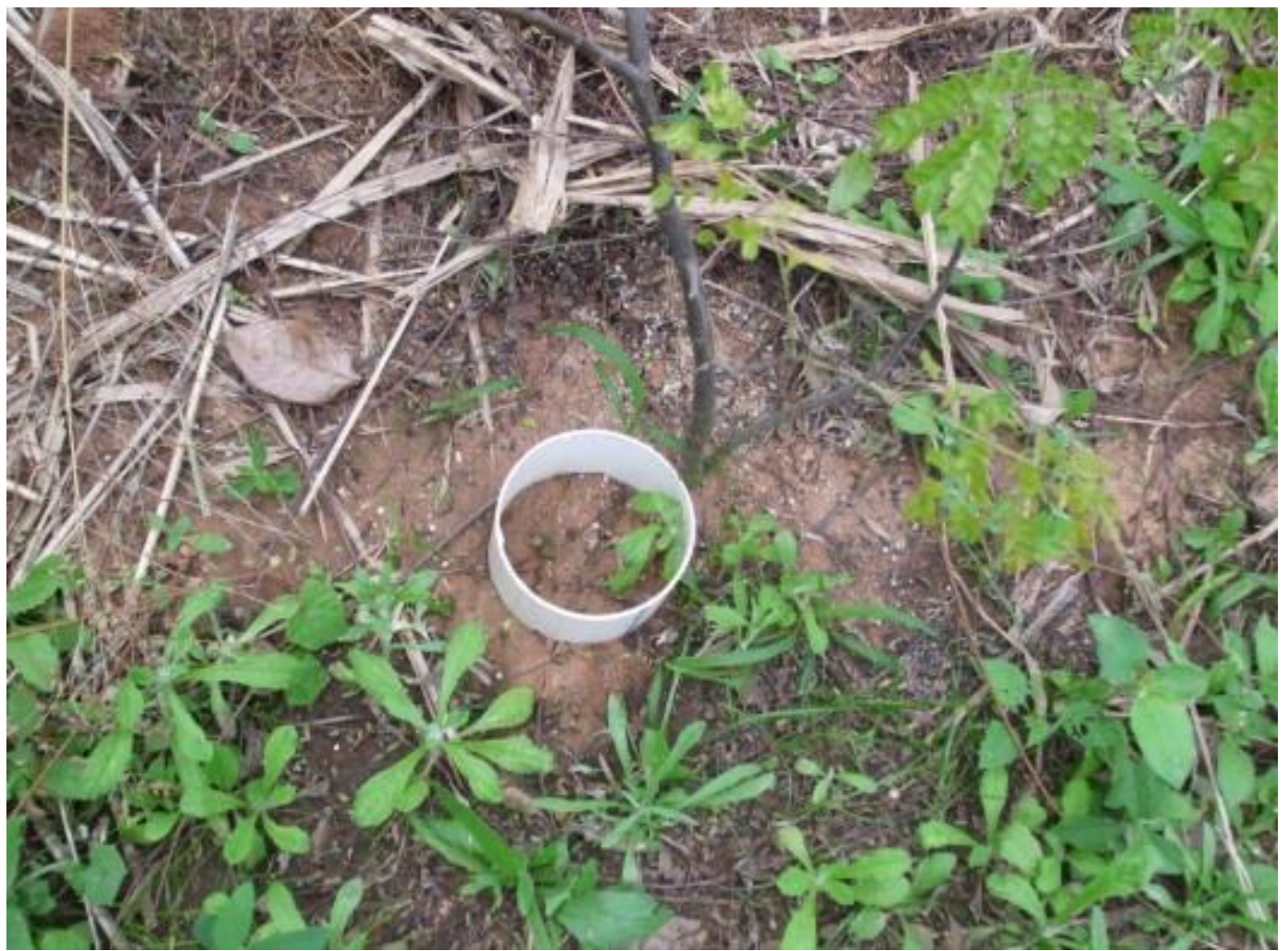

(Fonte: Autores).

Os valores da avaliação foram submetidos ao programa estatístico denominado ASSISTAT, versão 7,6 Beta (SILVA, 2012), onde foi utilizado o procedimento de análise de variância e ScottKnott, a $5 \%$ de probabilidade.

\section{RESULTADOS}

Após ser realizado a coleta e processamento dos dados, obtiveram-se os seguintes resultados, conforme é apresentado na tabela 1 e no gráfico 1.

Conforme tabela 1, conclui-se que houve diferença significativa entre os tratamentos. observa-se que os tratamentos 3 e 4 não tiveram diferença significativa entre si e considerados os melhores resultados. Já os tratamentos 1 e 2 obtiveram resultado igual estatisticamente e considerados os piores resultados.

Tabela 1. Resultado das avaliações de contagem de plântulas da vegetação, realizadas no período de 45 dias, conforme análise estatística, através do teste Scott-Knott.

\begin{tabular}{cc}
\hline Tratamento & Plântulas germinadas (médias) \\
\hline 2 & 14,11 \\
1 & 13,66 \\
5 & 6,40 \\
3 & 3,00 \\
4 & 2,22 \\
\hline
\end{tabular}

Obs.: médias seguidas pelas mesmas letras são consideradas estatisticamente iguais, através do teste Scott-Knott ( $p$ <0.05). Descrição dos tratamentos: $\mathrm{T} 1=$ Feijão de porco, $\mathrm{T} 2=$ Crotalária, $\mathrm{T} 3=$ Sombrite, $\mathrm{T} 4=$ Lona plástica, $\mathrm{T} 5=$ Testemunha. 
Gráfico 1. Avaliação da quantidade de plântulas de plantas daninhas germinadas (Fonte: Autores).
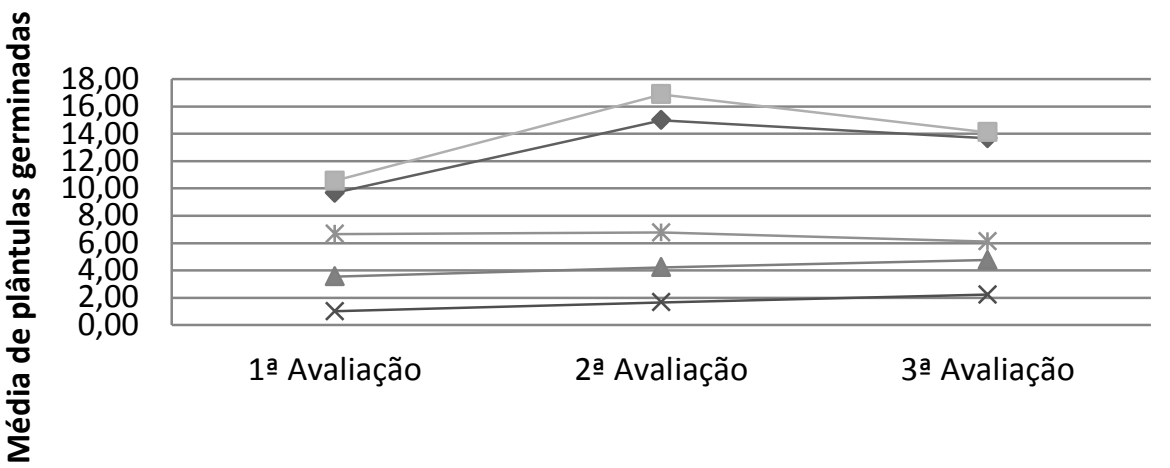

$\smile$ Feijão de porco

1ạ Avaliação

2a Avaliação

3a Avaliação

- Crotalária

- Sombrite

* Lona plástica

* Testemunha

\section{DISCUSSÃO}

Os tratamentos 3 e 4 apresentaram menos indivíduos de plântulas de ervas daninhas, pois aplicação desses tratamentos possibilitou sombreamento no local instalado, consequentemente dificultou a passagem de luminosidade no solo, impedindo a germinação de ervas daninhas. No tratamento 5 nenhum fator impediu a germinação do banco de sementes do local, considerando o resultado intermediário entre tratamentos.

Já os tratamentos 1 e 2 apresentaram mais indivíduos de plântulas de ervas daninhas, isso ocorreu devido as espécies utilizadas nos tratamentos terem um lento desenvolvimento inicial, consequentemente não foram capaz de impedir a germinação das erva daninhas que tem um desenvolvimento mais rápido.

\section{CONCLUSÃO}

Após o período de 45 dias, observou-se que o uso da lona plástica e sombrite foram mais eficazes em uma curta escala de tempo, pois foram os tratamentos que mais impediram a germinação e desenvolvimento das ervas daninhas. Tal resultado se atribui ao sombreamento exercido, uma vez que a lona impede totalmente a incidência de luz na superfície do solo e o sombrite impede a incidência de $50 \%$ da luz na superfície do solo.

Ressalta-se que é necessário responsabilidade no uso da lona e sombrite, realizando a retirada desses materiais após o início do sombreamento natural com o crescimento das árvores.

\section{REFERÊNCIAS}

BRASIL. Lei Federal no 12.651 de 25 de maio de 2012: Dispõe sobre a proteção de vegetação nativa. Disponível em:<http://www.planalto.gov.br/ccivil 03/ ato2011-

2014/2012/lei/l12651.htm>. Acesso: 08 jul 2017.

CEPAGRI. Centro de Pesquisas Meteorológicas e Climáticas Ligadas à Agricultura da Unicamp: Clima no município de Presidente Prudente-SP. Disponível em:

< http://www.cpa.unicamp.br/outras-informacoes/clima muni 467.html>. Acesso : 08 jul 2017.

EMBRAPA. Biologia e ecologia de plantas daninhas. Disponível em:

$<$ http://www.agencia.cnptia.embrapa.br/recursos/Plantas daninhas definicaolD-OKBSzkoJUb.pdf >. Acesso: 01 jul 2017. 
Instituto Brasileiro de Geografia e Estatística - IBGE: Mapa de biomas do Brasil - 2004a. Disponível em: < http://www.ibge.gov.br/home/presidencia/noticias/21052004biomas.shtm>. Acesso: 08 jul 2017.

Instituto Brasileiro de Geografia e Estatística - IBGE: Mapa de solos do Brasil - 2001. Disponível em: <http://mapas.ibge.gov.br/tematicos/solos>. Acesso: 08 jul 2017.

Instituto Brasileiro de Geografia e Estatística - IBGE: Mapa de vegetação do Brasil - 2004b.

Disponível em: < ftp://ftp.ibge.gov.br/Cartas e Mapas/Mapas Murais/>. Acesso : 08 jul 2017.

LORENZI, H. Árvores brasileiras: Manual de identificação e cultivo de plantas arbóreas nativas do Brasil. Plantarum, Nova Odessa, vol. 1. 5a Ed. 2010. 384p.

LORENZI, H. Manual de identificação e controle de plantas daninhas. São Paulo: Nova Odessa, 2006.

RAIJ, B. V. et al. (Eds.) Recomendações de adubação e calagem para o Estado de São Paulo. 2. ed. Campinas: Instituto Agronômico de Campinas, Fundação IAC, 1997.

RAMOS, V. S.; DURIGAN, G. FRANCO, G. A. D. C.; SIQUEIRA, M. F.; RODRIGUES, R. R. Árvores da Floresta Estacional Semidecidual: Guia de Identificação de espécies. São Paulo. Editora da Universidade de São Paulo: Biota/Fapesp, 2008. 320 p.

SILVA, F. de A. S. ASSISTAT versão 7.6 beta. Campina Grande: DEAG/CTRN/UFCG, 2012. 